\title{
Discovery Learning and the Computational Experiment in Higher Mathematics and Science Education: A Combined Approach
}

\author{
doi:10.3991/ijet.v4i4.1044 \\ A. Kyriazis ${ }^{1}$, S. Psycharis ${ }^{2}$ and K. Korres ${ }^{2}$ \\ ${ }^{1}$ University of Piraeus, Piraeus, Greece, \\ ${ }^{2}$ ASPETE (School of Pedagogical and Technological Education), Athens, Greece
}

\begin{abstract}
In this article we present our research for Discovery learning in relation to the computational experiment for the instruction of Mathematics and Science university courses, using the approach of the computational experiment through electronic worksheets. The approach is based on the principles of Discovery learning expanded with the principles of constructivist, socio-cultural and adult learning theories, the concept of computer based cognitive tools and the aspects on which the computational experiment is founded. Applications are presented using the software Mathematica and electronic worksheets for selected domains of Physics. We also present a case study, concerning the application of the computational experiment through electronic worksheets in the School of Pedagogical and Technological Education (ASPETE) during the spring semester of the academic year 2008-2009. Research results concerning the impact of the above mentioned issues on students' beliefs and learning performance are presented.
\end{abstract}

Index Terms-Discovery learning, Computational science, Cognitive tools, Electronic worksheets

\section{INTRODUCTION}

Contemporary research in Mathematics and Science Education points out the significance of the students' engagement in active discovery learning activities, learning in environments that have characteristics of active participation, self-action, exploration and experimentation. Also the significance of social learning is highlighted via the cooperation of the students with one another and with the teacher. The characteristics mentioned above come in contrast to the traditional teaching approach in higher education, the narration-based teaching.

Moreover Information Age has changed the needs of today's citizens, who are systematically trained and further educated. Businesses and organizations are developed and reorganized, organizing their personnel in autonomous groups with increased responsibilities. Employees who take initiative and introduce diverse points of view are in great demand. Communications are conducted mainly via networks and emphasis is laid on customization [11], [16]. Also technology is rapidly and constantly developed and initial education and training proves shortly to be inadequate.

Computers in Education originated in the early 1970's as Learning from computers (Computer Assisted Instruction-CAI), where computers were programmed to teach the students, keeping the principles of traditional instruction. In 1980's the emphasis was placed on Learning about computers, when numerous courses on mechanical parts of computers and programming emerged in almost every Secondary and Tertiary Education's Syllabus. Today the model of Computers as Cognitive tools is widely supported, where computers are used as intellectual partners of the students as they are involved in Discovery learning - constructivist activities [18].

Computational science is a quickly emerging field at the intersection of Science, Computer science and Mathematics because much scientific investigation now involves computing as well as theory and experiment [33], [28].

One of the crucial components of that research field is the correct abstraction of a physical phenomenon to a conceptual model and the translation into a computational model that can be validated. This leads us to the notion of a computational experiment where the model and the computer take the place of the "classical" experimental set-up and where simulation replaces the experiment as such.

This paper presents Discovery learning through the computational experiment, in teaching Mathematics and Science university courses, in particular the computational experiment through electronic worksheets. Moreover it studies the approach's impact on the students' learning performance and the students' beliefs concerning Physics and Mathematics.

In section 2 the theoretical framework is presented including the principles of Discovery learning, the concept of computer based cognitive tools and the views on which the computational experiment is founded. In section 3 Discovery learning through the computational experiment using electronic worksheets designed and implemented in Mathematica is presented and an application of teaching oscillation synthesis is presented. In section 4 the methodology of a case study is presented, concerning the application of the approach in the School of Pedagogical and Technological Education (ASPETE) during the spring semester of the academic year 2008-2009. In section 5 the results of the case study are presented. In section 6 some concluding remarks are discussed. 


\section{THEORETICAL FRAMEWORK}

\section{A. Discovery learning}

Discovery learning emerged initially in Bruner's theory [1], [2], according to which the teacher's main role is to help and encourage his/her students to discover the various concepts and ideas and to develop an aspect of exploration and experimentation towards knowledge. The constructivist and socio-cultural theories of learning added to the theoretical foundations of Discovery learning focusing on and expanding different aspects of the theory. In particular, according to Constructivism, developed by Piaget, Von Glasersfeld and other contemporary theorists and researchers, students construct knowledge actively, using their pre-existent knowledge [35], [38]. Learning is activated through the learner's actions in problematic situations [39]. According to Von Glasersfeld, knowledge is a process of adaptation with the world of experiences and not the discovery of a pre-existent world, independent to the learner.

Vygotsky's Social Development Theory, added to the social and cultural aspect of Discovery learning, claiming that every function in the learner's cultural development appears twice: initially in a social level and then in a personal level [42]. Humans in order to communicate with their social environment use "tools" (such as speech, written speech, cognitive tools); the internalization of these tools leads to higher order thinking skills [6].

Discovery learning in Higher education should include conditions of adult learning theories, since students who attend university lessons have both the characteristics of adolescent students (studied by Pedagogy) and adult learners, as stated by Cross [7] and Zemke and Zemke [44]. According to Knowles' Andragogy, adults are selfdirected and want to participate in the programming and evaluation of their teaching. Adult learners have a wealth of experience that becomes a resource for learning, so teaching should take into consideration the wide range of different backgrounds of the learners. Adult learners learn better when the object of learning is directly related to their work or personal life. Adult learners' motives to learn are basically internal, so the teacher's role is to facilitate learning, rather than to lecture or to grade the learners [21], [22].

\section{B. Cognitive tools}

Traditional views concerning the use of computers in teaching and learning (learning from computers) resulted in the definition of educational software as the means of the educational process that aims at the facilitation of learning using computers as the basic tool. Kemmis, Atkin and Wright [19] initially proposed a framework for Computer Aided Learning (CAL), including all the activities via which computers contribute to the learning process in various ways, defining four paradigms: a) Instructional model or Computer Assisted Instruction - CAI, b) Relevatory model or Simulation, c) Conjectural model or Modeling and d) Emancipatory model.

According to Scardamalia \& Bereiter, computer learning environments, if appropriately designed, can support constructivist and exploratory learning, giving learners more agency in the learning process [32], [12]. Especially simulation-based learning involves learning performed in a computerized environment, in which the learner inter- acts with the entities of the environment and gradually infers the features of the concept model whilst he/she proceeds through the simulation, which may lead to changes in his/her original concept [41].

The discussion on whether computerized environments improve learning performance is currently continuing. There are studies' outcomes according to which simulation-based learning does not significantly improve the test results of learners [29], [31], other outcomes that do not prove significant differences between simulation-based and narration-based teaching [3] and others that prove significant advantages of simulation-based learning [4], [5], [25].

Today's most appealing model of Computer Aided Learning is "Computers as cognitive tools". According to Jonassen [18], cognitive tools or mindtools are learning environments and computer based tools that have been developed or adjusted, in order to function as "intellectual partners" of the students, in order to activate and accommodate critical thinking and higher order learning.

Cognitive tools have the following characteristics:

- They are generalizable computational tools [18].

- They reorganize (radically reconstruct) the way learners think [26].

- They aim in activating and facilitating the cognitive process [23].

- They support, guide and extend the thinking processes of their users [9].

- They are not just accommodating tools [18], neither "fingertip" tools [27].

- They are critical thinking devices [18].

- The tools create an "Intellectual Scaffolding" towards "meaningful thinking" [18].

- They support knowledge construction and transferable learning [18].

- They have simple, powerful formalism and they are easily learnable [18].

\section{The computational experiment}

According to Sloot [36], Computational Science (CSE) aims to create reliable computational experiments. The functional stages in the development of a computer experiment are: Physical phenomenon, Mathematical model, Discrete algebraic approximation, Numerical algorithm, Simulation, Computer experiment.

Sloot [36] identifies three major phases in the process of the development of a computer experiment, each with its own challenges:

- The modeling phase. The first step to simulation is the development of an abstract model of the physical system under study.

- The simulation phase. Here we refer to (mathematical) methods that make the underlying physical models discrete and a rough distinction can be made between solvers for Discrete Event systems and solvers for Continues systems. The more conventional solvers are Finite Difference, Finite Element/Volume and a large class of linear algebra solvers.

- The computational phase. In this phase we concentrate on the mapping of the different solvers to the machine architecture. Since the types of problems we 
are interested in are computationally very demanding, lots of research effort in the efficient use of modern architectures for simulation is going on in this field.

Landau et al. [24] suggest an approach similar to Sloot's approach. They organize the steps of the Computational science in the framework of a scientific problemsolving as follows:

Prob-

lem $\leftrightarrow$ Theory $\leftrightarrow$ Model $\leftrightarrow$ Method $\leftrightarrow$ Implementation $\leftrightarrow$ Assessment.

They state that Computational Physics, Computational Mathematics, Engineering etc. are subfields of Computational Science (CSE) and as multidisciplinary subjects, they combine aspects of Physics (Engineering, Biology, etc.), Applied mathematics and Computer Science (CS) with the aim of solving realistic problems.

We have to distinguish between computational science and computer science since, although related, computational science is not computer science. Computer science studies for its own intrinsic interest and develops the hardware and software tools that computational scientists use. Likewise, Applied Mathematics develops and studies the algorithms that computational scientists use. As much as Mathematics and Computer Science are interesting for their own sakes, our focus is on solving physical problems; we need to understand the CS and math tools well enough to be able to solve our problems (for education) correctly.

Landau et al. [24] emphasize their computational science focus in the form of a problem to solve, with the components that constitute the solution separated according to the scientific problem-solving paradigm. In this framework, being able to transform a theory into an algorithm requires significant theoretical insight, detailed physical and mathematical understanding and a mastery of the art of programming and the actual debugging, testing, and organization of scientific programs is analogous to experimentation, with the numerical simulations of nature being essentially virtual experiments. The scientific paradigm should include modeling and simulation as an additional dimension in order to create computational experiments.

The Scientific Paradigm of Landau et al. is summarized as follows:

Problem (from science), Modeling (discrete, continuous), Simulation Method (numeric, symbolic), Implementation (Mathematica, Java etc.) and finally Assessment and Visualization/exploration.

The format of Computational Science proposed by Sloot [36] and Landau et al. [24] places the subject matter in its broader context and indicates how the steps are applicable to a wider class of problems. Most importantly, educational assessments and surveys have indicated that some students learn science, mathematics and technology better when they are presented together in context rather than as separate subjects. Likewise, some students who may not profess interest in Mathematics or CS are motivated to learn these subjects by experiencing their practical value in science problem solving.

This view is also supported by Guzdial [15]. He states that today, education researchers are more interested in programming as a medium, as a way of thinking about and exploring disciplines other than computer science [10], [37].

In his paper Guzdial [15] says that we are still interested in having students learn about programming, because we view programming as an important skill and as a medium of communication. But now we are even more interested in having students learn through programming because we recognize that programming is a good lever for understanding many domains.

\section{Students' beliefs on Physics and Mathematics}

Redish and Hammer [30] classify students' beliefs along three dimensions: Independence/authority, Coherence/pieces and Concepts/equations. Redish and Hammer's definitions on the students' beliefs on Physics and Mathematics are presented in Table I.

TABLE I.

DEFINITION OF STUDENTS' BELIEFS

\begin{tabular}{|c|c|c|}
\hline & \multicolumn{2}{|c|}{ Beliefs on Physics and Mathematics } \\
\hline & Favourable & Unfavourable \\
\hline Independence & $\begin{array}{l}\text { Learns independently, } \\
\text { believes in their own } \\
\text { need to evaluate and } \\
\text { understand }\end{array}$ & $\begin{array}{l}\text { Takes what is given by } \\
\text { authorities (teacher, } \\
\text { text) without evalua- } \\
\text { tion }\end{array}$ \\
\hline Coherence & $\begin{array}{l}\text { Believes physics needs to } \\
\text { be considered as a con- } \\
\text { nected, consistent } \\
\text { framework }\end{array}$ & $\begin{array}{l}\text { Believes physics can } \\
\text { be treated as separated } \\
\text { facts or "pieces" }\end{array}$ \\
\hline Concepts & $\begin{array}{l}\text { Stresses understanding } \\
\text { of the underlying ideas } \\
\text { and concepts }\end{array}$ & $\begin{array}{l}\text { Focuses on memoriz- } \\
\text { ing and using formulas }\end{array}$ \\
\hline Reality link & $\begin{array}{l}\text { Believes ideas learned in } \\
\text { physics are useful in a } \\
\text { wide variety of real- } \\
\text { world contexts }\end{array}$ & $\begin{array}{l}\text { Believes ideas learned } \\
\text { in physics are unre- } \\
\text { lated to experiences } \\
\text { outside the classroom }\end{array}$ \\
\hline Math link & $\begin{array}{l}\text { Considers mathematics } \\
\text { as a convenient way of } \\
\text { representing physical } \\
\text { phenomena }\end{array}$ & $\begin{array}{l}\text { Views Physics and } \\
\text { Mathematics as inde- } \\
\text { pendent with no strong } \\
\text { relationship between } \\
\text { them }\end{array}$ \\
\hline
\end{tabular}

\section{THE COMPUTATIONAL EXPERIMENT USING} ELECTRONIC WORKSHEETS IN MATHEMATICA

\section{A. Discovery learning through the computational experiment}

According to de Jong [8], inquiry (discovery) learning is defined as "an approach to learning that involves a process of exploring the natural or material world and that leads to asking questions, making discoveries and rigorously testing those discoveries in the search for new understanding".

Our challenge is to combine scientific inquiry and the computational experiment as the path to create/organize a student-centered instructional design. Scientific practice for students should contain the modeling, the algorithmic approach and the simulation of the phenomena which is the realm of the computational science [36].

Scientific practice involves also the construction, validation and application of scientific models, so science instruction (using the scientific inquiry learning) should be designed to engage students in making and using scientific models which are considered as coherent units of structured knowledge [17]. Therefore, the structure of scientific 
knowledge can be made more explicit for students by organizing course content around a small number of basic models. The ability of students to make and use models depends on the representational tools at their command. Students learn transferable modeling skills by applying given models to a variety of situations to describe, explain or predict physical events or to design experiments.

Scientific practice for students (at all levels of education) should provide students with basic conceptual tools for modeling physical objects and processes, especially mathematical, graphical and diagrammatic representations. In addition to that, scientific inquiry for students should help them to develop insight into the structure of scientific knowledge by examining how models fit into theories and to show how scientific knowledge is validated by engaging students in evaluating scientific models through comparison with empirical data.

Models are simultaneously important outcomes of science and relevant components of scientific methodology and through modeling, students should: (i) be introduced to the most significant scientific models; (ii) become able to appreciate the scope and limitations of such models; and (iii) be engaged in both modeling activities and discussions concerning the use of the models that they produce [13].

In this framework, Instructional design should be organized into the sequences of the computational experiment, which should engage students in all phases of model development, evaluation and application in concrete situations - thus promoting an integrated understanding of modeling processes and acquisition of coordinated modeling skills.

Students would also be encouraged to present and justify their conclusions in oral and/or written form, including a formulation of models for the phenomena in question and evaluation of the models by comparison with data.

\section{B. The computational experiment via electronic work- sheets in Mathematica}

We propose the creation and use of electronic worksheets containing the phases of the computational experiment, in the environment of a cognitive tool.

A very promising cognitive tool in teaching Mathematics and Science courses is Mathematica [43], [40], [14], mainly because:

a) Its mathematical operations' notation and objects are similar to the standard mathematical notation,

b) It has a function-based structure, which allows us to define and study objects and quantities as real functions of real variables and

c) It offers possibilities in plotting graphs easily, quickly and precisely and in making complex calculations quickly and accurately.

Electronic worksheets created in the environment of Mathematica function both as word processors and as dynamic, interactive notebooks of Mathematica, that means the students can run the commands and the programs that are handed out by the worksheet, they can alter the parameters, the plot margins and the expressions of the commands and the programs and run them again and they can write their answers to the questions posed typing in the free spaces of the worksheet.
Shunn and Klahr [34] and Klahr and Dunbar [20], in order to describe discovery learning as a search process, introduced spaces in scientific discovery learning that include the hypothesis space and the experiment space. In Klahr and Dunbar's model the hypothesis space contains all rules and variables describing the specific domain while the experiment space consists of all experiments that can be implemented within this domain.

Van Joolingen and De Jong [41] extended Klahr and Dunbar's model introducing different sub-domains in hypothesis space and proposed a taxonomy to describe relevant search operations in every space. The knowledge representations introduced by Van Joolingen and De Jong's model are not static, but they involve a time dependent evolution when students gain knowledge about the underlying model leading to a shift from their learner domain space toward the target conceptual model.

Van Joolingen and De Jong [41] consider that the universal hypothesis space (the set of hypotheses that can be stated in principle) and the target conceptual model (the set of hypotheses that describes the domain to be discovered) are fixed and that during discovery learning approach there could be a change only for the learner's hypothesis space and the learner's domain space. According to Van Joolingen and De Jong the change in learner's hypothesis space could happen, for example, when the learner discovers new relations that can be used in creating new hypotheses, while the learner's domain could change during experimentation.

Based on the principles mentioned above, the electronic worksheets in Mathematica, should include:

A) The hypotheses space, where the students in cooperation with the teacher decide, clarify and state the hypotheses of the problem/ problems or the subject domain to be studied.

B) The experiments space, where the computational experiment actually takes place, that includes simulation based discovery learning activities via which the students, through discussion and social interaction with their peers and the teacher, actively construct and formulate conclusions, generalizations of results and solutions on the problems or subjects under negotiation.

C) The predictions space, where the results, conclusions or solutions formulated in the experiments space are checked with the analytical (mathematical) solutions of the problem/ problems or the analytical negotiation or the subject domain to be studied, in order to check their credibility.

\section{Electronic worksheet on oscillation synthesis}

Below we present an electronic worksheet in Mathematica that contains the computational experiment on oscillation synthesis as presented above. The electronic worksheet basically contains two characteristic problems on oscillation synthesis. The first and second problems involve the study of oscillation synthesis for oscillations with different widths - same frequencies and same widths - different frequencies correspondingly.

The electronic worksheet contains the following parts (see Figures 1.a., 1.b., 1.c., 1.d., 1.e., 1.f., 1.g. and 1.h.):

1. Hypotheses space

a. Activity on oscillations

b. Setting the problem of oscillation synthesis 
c. Setting the hypotheses, the variables and the relations between variables of the $1^{\text {st }}$ problem

d. Setting the hypotheses, the variables and the relations between variables of the $2^{\text {nd }}$ problem

2. Experiments space

a. Experimental solution of the $1^{\text {st }}$ problem

b. Experimental solution of the $2^{\text {nd }}$ problem

3. Predictions space

a. Analytical solution of the $2^{\text {nd }}$ problem

b. Credibility of the results of the $2^{\text {nd }}$ problem

\section{The Methodology of the CASe Study}

\section{A. Description of the case-study}

The case-study involves the application of the computational experiment via electronic worksheets in Mathematica in ASPETE (School of Pedagogical and Technological Education) and the study of the approach' s impact on students' scores and the students' beliefs on Physics and Mathematics. The application of the approach was implemented in a class of 20 students, attending the course "Pedagogical Applications of Computers".

Two research questions were posed and are answered by this paper:

1st research question: Does the computational experiment using electronic worksheets in Mathematica have an impact on students' scores in tests concerning the subjects taught?

2nd research question: Is there a shift on students' beliefs regarding Physics and Mathematics that can be attributed to the approach?

Two questionnaires were designed and implemented, being handed out to the students the first before and the second after the application of the approach. Both questionnaires included two parts: The first part aimed at evaluating students' understanding of the cognitive subject taught and the second part aimed at evaluating students' beliefs on Physics and Mathematics, as defined by Redish and Hammer [30].

The cognitive subject selected is oscillation synthesis, a subject that all students have been taught both in high school, being included in the content that the students were prepared to be examined at the formal state Greek Entry Examinations, but also in the students' studies in ASPETE. In this way differences in students' scores in the two tests before and after the application of the approach can be attributed to the approach. Also differences in students' beliefs on Physics and Mathematics before and after the application of the approach can also be attributed to the approach.

\section{B. The teaching approach}

The experiment lasted for 6 hours. The lessons took place in the computer laboratory, with the students working in groups of 2 students per computer. The students cooperated with the members of their group, with members from other teams and with the teacher in dealing with the problematic situations they came across while working with the electronic worksheet. They were given the opportunity to set into discussion questions, conjectures and conclusions to the community of the class and to ask at any time the help of the teacher, regarding the understand-

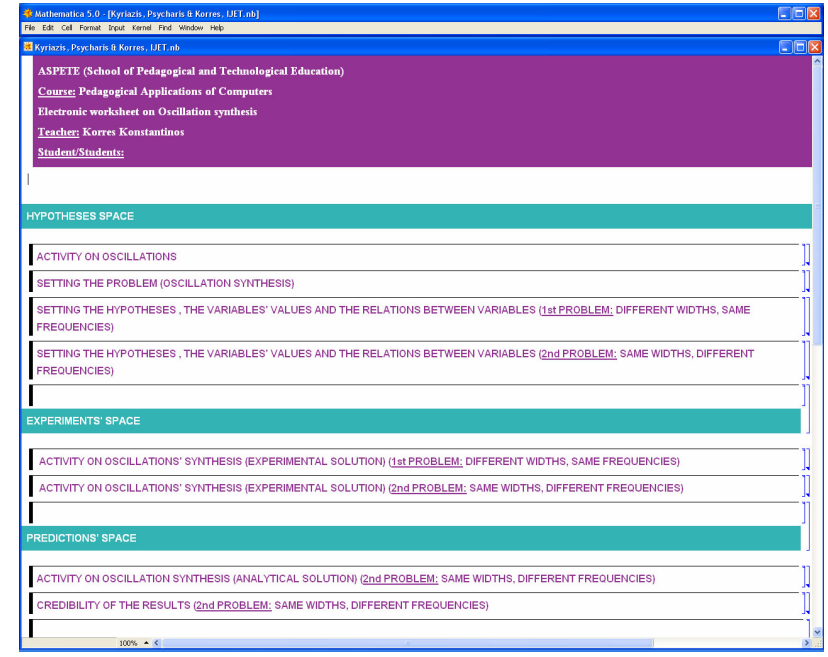

Figure 1.a. Electronic worksheet on oscillation synthesis - Starting screen

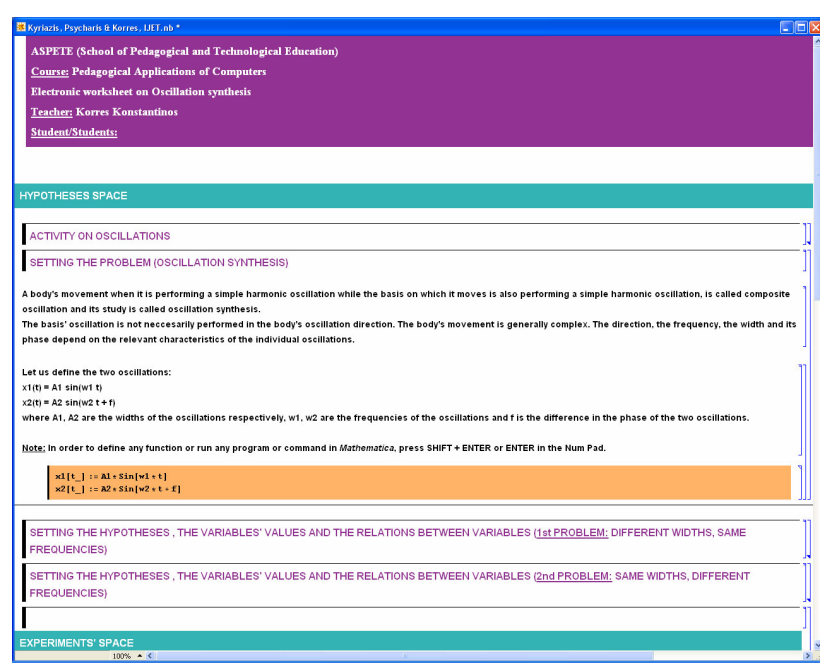

Figure 1.b. Electronic worksheet on oscillation synthesis - Hypotheses space: Setting the problem

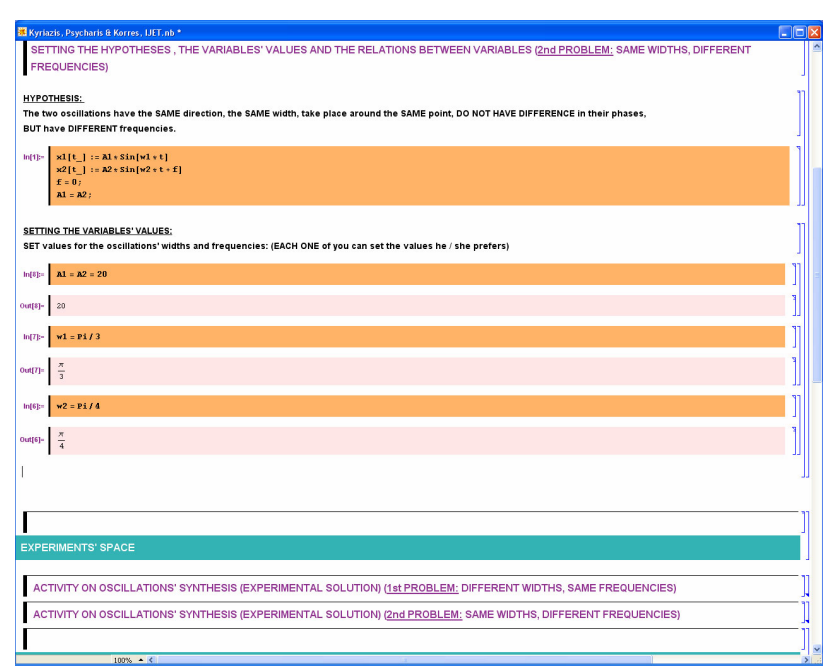

Figure 1.c. Electronic worksheet on oscillation synthesis - Hypotheses space: Setting the hypotheses, the variables and the relations between variables of the $2^{\text {nd }}$ problem (same widths, different frequencies) 


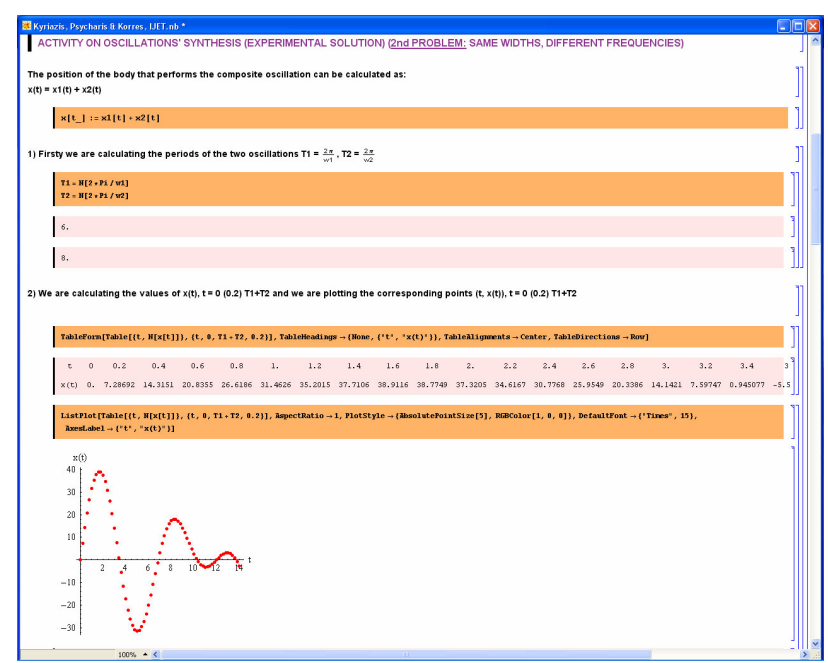

Figure 1.d. Electronic worksheet on oscillation synthesis - Experiments space: Experimental solution of the $2^{\text {nd }}$ problem ( $1^{\text {st }}$ screen $)$

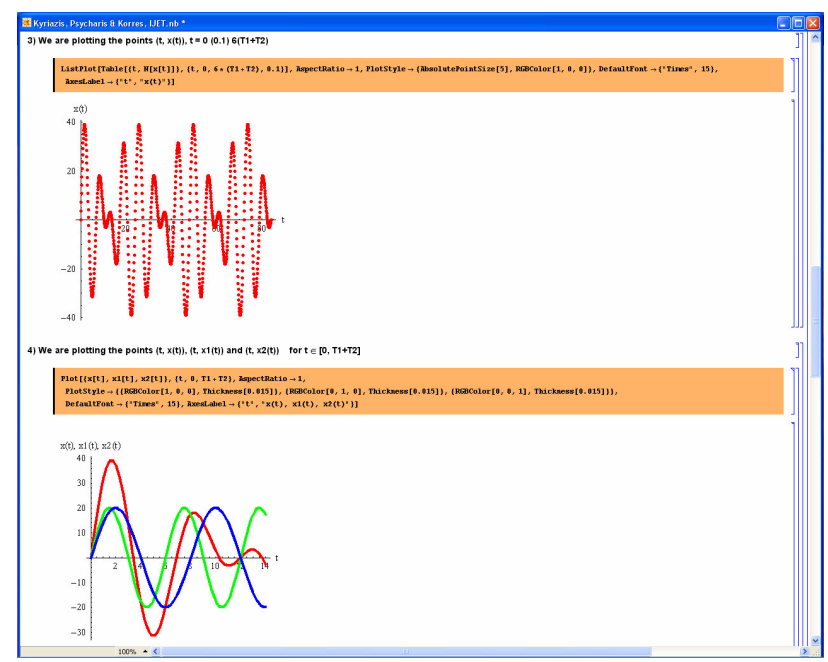

Figure 1.e. Electronic worksheet on oscillation synthesis - Experiments space: Experimental solution of the $2^{\text {nd }}$ problem $\left(2^{\text {nd }}\right.$ screen $)$

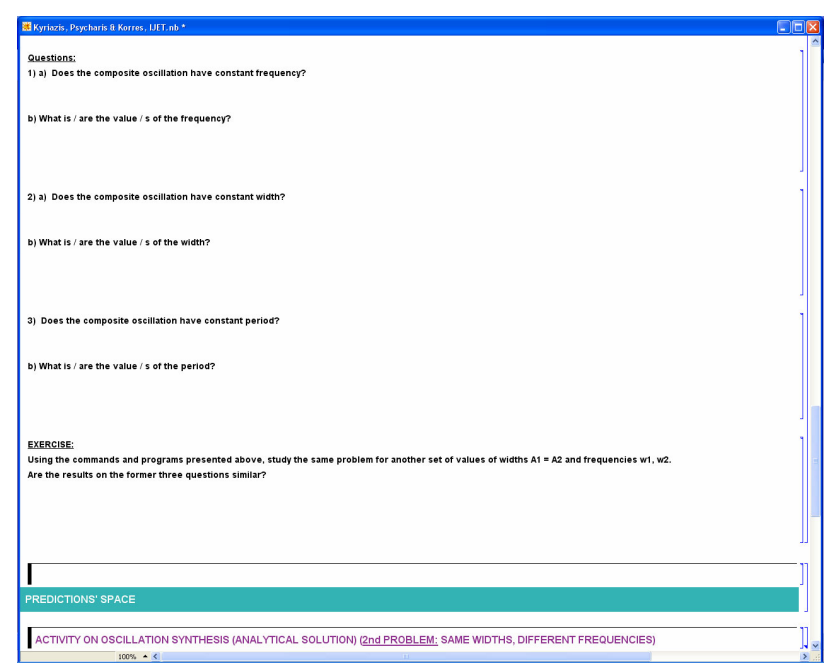

Figure 1.f. Electronic worksheet on oscillation synthesis - Experiments space: Experimental solution of the $2^{\text {nd }}$ problem $\left(3^{\text {rd }}\right.$ screen $)$

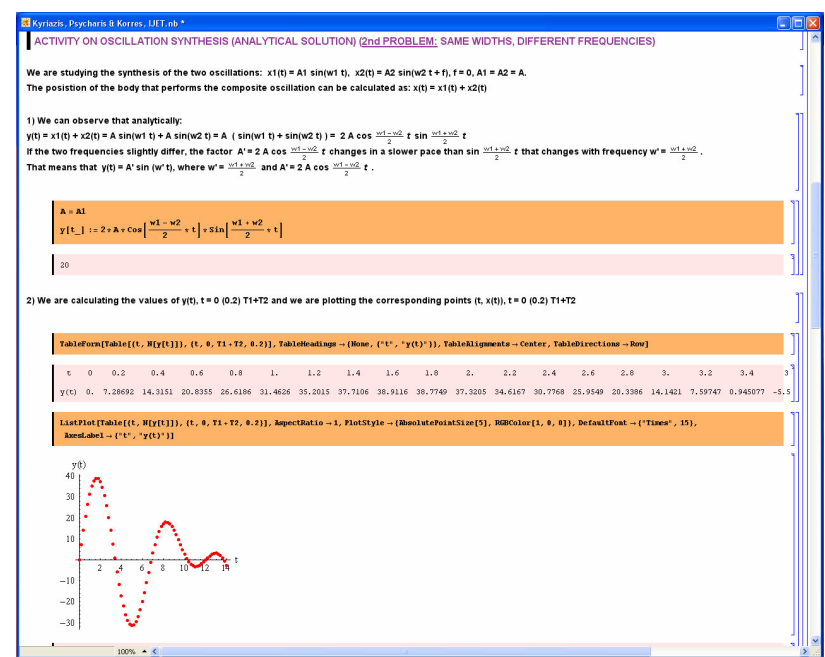

Figure 1.g. Electronic worksheet on oscillation synthesis - Predictions space: Analytical solution of the $2^{\text {nd }}$ problem

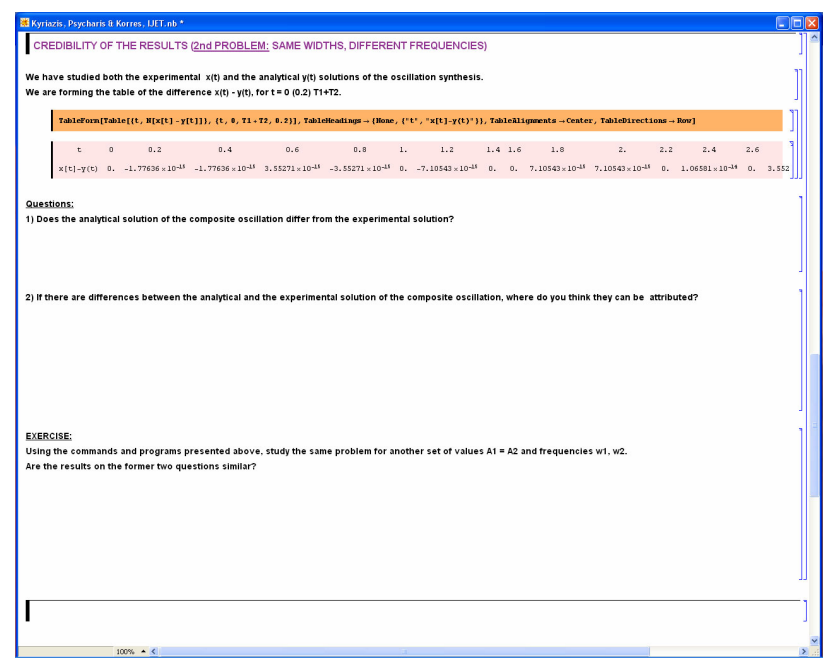

Figure 1.h. Electronic worksheet on oscillation synthesis - Predictions space: Credibility of the results of the $2^{\text {nd }}$ problem

ing of the concepts referred to at the lesson and the use, the syntax and the function of the software's commands. The teacher wrote on the board the elements of theory he regarded as necessary, the commands and programs of Mathematica, the conjectures, the hypotheses and the conclusions formulated by the students and with the use of a video - projector, he presented to students static and dynamic representations (animations), relevant to the subjects under negotiation. Also notes were handed out to the students at the start of every lesson containing the lesson's main elements

The computational experiment via electronic worksheets in Mathematica on oscillation synthesis had the following stages:

At the first stage, the students were guided to work in groups of two students with a basic problem on oscillations and afterwards to discuss the setting of the problem of oscillation synthesis at the Hypotheses space, at the start of the lesson.

The second stage involved the students working with the $1^{\text {st }}$ problem in Hypotheses space (Setting the hypothe- 


\section{DISCOVERY LEARNING AND THE COMPUTATIONAL EXPERIMENT IN HIGHER MATHEMATICS AND SCIENCE EDUCATION: A COMBINED APPROACH}

ses) and Experiments space (Experimental solution), with the teacher basically teaching those activities and the students working at the same pace all together and discussion taking place during that process.

At the third stage, the students were guided to work in groups of two students with the $2^{\text {nd }}$ problem individually in Hypotheses space (Setting the hypotheses), in Experiments space (Experimental solution) and in Predictions space (Analytical solution) and then they discussed with the teacher and the whole class the Credibility of the results' part in Predictions space.

\section{RESULTS}

\section{A. The students that participated in the study}

The students that participated in the study were 20 students of ASPETE, attending the course "Pedagogical Applications of Computers". The participation in the study was on a voluntary basis and the questionnaires were answered anonymously, with the registration number of the students to be the only personal data filled in at the questionnaires, in order for pre and post questionnaires to be correspondent for every student.

Regarding gender, $40 \%$ of the students were males and $60 \%$ females. Regarding age, the students had mean age 20.16 with standard deviation 2.5 , having minimum age 19 and maximum age 30 years.

\section{B. Students'scores}

The students' scores before and after the application of the approach present significant differences since the students before the approach had mean score 3.35 with standard deviation 2.80 while after the approach they had mean score 6.15 with standard deviation 2.48 (see Table II).

TABLE II.

DESCRIPTIVE MEASURES FOR STUDENTS' SCORES

\begin{tabular}{|c|c|c|c|c|c|}
\hline & \multicolumn{5}{|c|}{ Descriptive measures } \\
\cline { 2 - 6 } & $\boldsymbol{N}$ & Minimum & Maximum & Mean & $\begin{array}{c}\text { St. } \\
\text { Devia- } \\
\text { tion }\end{array}$ \\
\hline Score (pre) & 20 & 0.0 & 8.0 & 3.35 & 2.80 \\
\hline Score (post) & 20 & 2.0 & 10.0 & 6.15 & 2.48 \\
\hline
\end{tabular}

The difference between the students' scores before and after the application of the approach can also be validated by the results of the Inferential Analysis and specifically via the Paired Samples t-test.

The paired samples $\mathrm{t}-$ test has as a precondition the differences of the values of the students' scores before and after the approach to come from a population with normal distribution. One Sample Kolmogorov-Smirnov test for the differences $d_{i}=S$ core $(\text { post })_{i}-S c o r e(p r e)_{i}, i=1(1) 20$, showed: $Z=0.753, p=0.622$, so the precondition of paired samples t-test is satisfied.

The results of the paired samples $t$-test showed that Pearson's correlation coefficient is $\mathrm{r}=0.820, p<0.001$, so there is a strong linear correlation between the two variables.

The mean value of the differences between students' scores equals to -2.8 , with the corresponding $95 \%$ confidence interval to be from -3.55 to -2.05 . Since the confi- dence interval does not contain the value 0 , there is difference in the mean scores of the students, with 0.05 probability of error. The value of $\mathrm{t}$-test is $\mathrm{t}=-7.782, \mathrm{df}=19, p$ $<0.01$, with the negative sign stating that the mean value in students scores before the approach is lower than the mean value of the scores after the approach.

By observing the students' scores distributions (see Table III), we can conclude that before the application of the approach $35 \%$ of the students scored 5 and above compared to $65 \%$ of the students after the application. Also before the application only $5 \%$ of the students scored 8 and above and $0 \% 9$ or 10 , compared to $35 \%$ and $15 \%$ of the students after the application of the approach correspondingly.

TABLE III.

DISTRIBUTION OF STUDENTS' SCORES

\begin{tabular}{|c|c|c|c|c|}
\hline \multirow{2}{*}{ Scores } & \multicolumn{4}{|c|}{ Students' scores } \\
\cline { 2 - 5 } & \multicolumn{2}{|c|}{ Score (pre) } & \multicolumn{2}{c|}{ Score (post) } \\
\cline { 2 - 5 } & Frequency & Percent & Frequency & Percent \\
\hline $\mathbf{0}$ & 7 & 35.0 & 0 & 0.0 \\
\hline $\mathbf{1}$ & 0 & 0.0 & 0 & 0.0 \\
\hline $\mathbf{2}$ & 0 & 0.0 & 1 & 5.0 \\
\hline $\mathbf{3}$ & 1 & 5.0 & 1 & 5.0 \\
\hline $\mathbf{4}$ & 5 & 25.0 & 6 & 30.0 \\
\hline $\mathbf{5}$ & 2 & 10.0 & 1 & 5.0 \\
\hline $\mathbf{6}$ & 2 & 10.0 & 1 & 5.0 \\
\hline $\mathbf{7}$ & 2 & 10.0 & 3 & 15.0 \\
\hline $\mathbf{8}$ & 1 & 5.0 & 4 & 20.0 \\
\hline $\mathbf{9}$ & 0 & 0.0 & 0 & 0,0 \\
\hline $\mathbf{1 0}$ & 0 & 0.0 & 3 & 15.0 \\
\hline Total & 20 & 100,0 & 20 & 100,0 \\
\hline
\end{tabular}

\section{Students' beliefs on Physics and Mathematics}

Students' beliefs on Physics and Mathematics regarding Independence do not present significant change compared before and after the application of the computational experiment via electronic worksheets. $30 \%$ stated that they learn independently before the application of the approach compared to $40 \%$ after the application (see Table IV).

That result is also validated by the results of the Inferential Analysis, since $\mathrm{X}^{2}-$ Testing for Independence gave the results: $\mathrm{X}^{2}=6.706, p=0.01(<0.05)$, so the two variables can be regarded as dependent for significance level 5 $\%$.

Also McNemar test for equality of percentages ( $p=$ 0.625 ) showed that there is not a statistically significant difference in the students' beliefs regarding independence before and after the application of the approach.

TABLE IV.

STUDENTS' BELIEFS ON PHYSICS AND MATHEMATICS - INDEPENDENCE

\begin{tabular}{|c|c|c|}
\hline $\begin{array}{c}\text { Beliefs on Physics and } \\
\text { Mathematics }\end{array}$ & \multicolumn{2}{|c|}{ Independence(post) } \\
\hline $\begin{array}{c}\text { Independence(pre) } \\
\text { Learns } \\
\text { independently }\end{array}$ & $\begin{array}{c}\text { Takes what is } \\
\text { given by authori- } \\
\text { ties }\end{array}$ \\
\hline $\begin{array}{c}\text { Leakes what is given by } \\
\text { authorities }\end{array}$ & 5 & 1 \\
\hline
\end{tabular}




\section{DisCOVERY LEARNING AND THE COMPUTATIONAL EXPERIMENT IN HIGHER MATHEMATICS AND SCIENCE EDUCATION: A COMBINED APPROACH}

Students' beliefs on Physics and Mathematics regarding Coherence before and after the application of the approach seem to present significant change, since $35 \%$ of the students stated that Physics needs to be considered as a connected, consistent framework before the application of the approach compared to $63.2 \%$ afterwards (see Table V).

That result is validated by the results of $\mathrm{X}^{2}-$ Testing for Independence: $\mathrm{X}^{2}=0.652, p=0.419(>0.05)$, so the two variables can be regarded as independent for significance level $5 \%$.

McNemar test for equality of percentages however ( $p=$ 0.146 ) showed that there is not a statistically significant difference in the students' beliefs regarding coherence before and after the application of the approach.

TABLE V.

STUDENTS’ BELIEFS ON PHYSICS AND MATHEMATICS - COHERENCE

\begin{tabular}{|c|c|c|}
\hline $\begin{array}{c}\text { Beliefs on Physics and } \\
\text { Mathematics }\end{array}$ & \multicolumn{2}{|c|}{ Coherence (post) } \\
\hline Coherence (pre) & $\begin{array}{c}\text { Physics needs to } \\
\text { be considered as } \\
\text { a connected, } \\
\text { consistent } \\
\text { framework }\end{array}$ & $\begin{array}{c}\text { Physics can be } \\
\text { treated as sepa- } \\
\text { rated facts or } \\
\text { "pieces" }\end{array}$ \\
\hline $\begin{array}{c}\text { Physics needs to be consid- } \\
\text { ered as a connected, consis- } \\
\text { tent framework }\end{array}$ & 3 & 3 \\
\hline $\begin{array}{c}\text { Physics can be treated as } \\
\text { separated facts or "pieces" }\end{array}$ & 9 & 4 \\
\hline
\end{tabular}

Students' beliefs regarding Concepts before and after the application of the approach do not present significant change, since $70 \%$ of the students stated that they stress understanding of the underlying ideas and concepts before the application of the approach compared to $75 \%$ afterwards (see Table VI).

That result is validated by the results of $\mathrm{X}^{2}-$ Testing for Independence: $\mathrm{X}^{2}=7.937, p=0.005(<0.05)$, so the two variables can be regarded as dependent and McNemar test for equality of percentages $(p=1.000)$.

TABLE VI.

STUDENTS' BELIEFS ON PHYSICS AND MATHEMATICS - CONCEPTS

\begin{tabular}{|c|c|c|}
\hline $\begin{array}{c}\text { Beliefs on Physics and } \\
\text { Mathematics }\end{array}$ & \multicolumn{2}{|c|}{ Concepts (post) } \\
\hline Concepts (pre) & $\begin{array}{c}\text { Stresses under- } \\
\text { standing of the } \\
\text { underlying ideas } \\
\text { and concepts }\end{array}$ & $\begin{array}{c}\text { Focuses on memo- } \\
\text { rizing and using } \\
\text { formulas }\end{array}$ \\
\hline $\begin{array}{c}\text { Stresses understanding of } \\
\text { the underlying ideas and } \\
\text { concepts }\end{array}$ & 13 & 1 \\
\hline $\begin{array}{c}\text { Focuses on memorizing } \\
\text { and using formulas }\end{array}$ & 2 & 4 \\
\hline
\end{tabular}

Students' beliefs regarding Reality link before and after the application of the approach are exactly the same, since the total of the students stated that ideas learned in physics are useful in a wide variety of real world contexts (see Table VII).

Students' beliefs regarding Math link before and after the application of the approach do not present significant change, since $90 \%$ of the students stated that Mathematics is a convenient way of representing physical phenomena before the application of the approach compared to 95 $\%$ afterwards (see Table VIII).
TABLE VII.

STUDENTS' BELIEFS ON PHYSICS AND MATHEMATICS - REALITY LINK

\begin{tabular}{|c|c|c|}
\hline $\begin{array}{c}\text { Beliefs on Physics and } \\
\text { Mathematics }\end{array}$ & \multicolumn{2}{|c|}{ Reality link (post) } \\
\hline Reality link (pre) & $\begin{array}{c}\text { Ideas learned in } \\
\text { physics are } \\
\text { useful in a wide } \\
\text { variety of real } \\
\text { world contexts }\end{array}$ & $\begin{array}{c}\text { Ideas learned in } \\
\text { physics are unre- } \\
\text { lated to experi- } \\
\text { ences outside the } \\
\text { classroom }\end{array}$ \\
\hline $\begin{array}{c}\text { Ideas learned in physics are } \\
\text { useful in a wide variety of } \\
\text { real world contexts }\end{array}$ & 20 & 0 \\
\hline $\begin{array}{c}\text { Ideas learned in physics are } \\
\text { unrelated to experiences } \\
\text { outside the classroom }\end{array}$ & 0 & 0 \\
\hline
\end{tabular}

TABLE VIII.

STUDENTS' BELIEFS ON PHYSICS AND MATHEMATICS - MATH LINK

\begin{tabular}{|c|c|c|}
\hline $\begin{array}{c}\text { Beliefs on Physics and } \\
\text { Mathematics }\end{array}$ & \multicolumn{2}{|c|}{ Math link (post) } \\
\hline Math link (pre) & $\begin{array}{c}\text { Mathematics is a } \\
\text { convenient way } \\
\text { of representing } \\
\text { physical phe- } \\
\text { nomena }\end{array}$ & $\begin{array}{c}\text { Physics and math } \\
\text { are independent } \\
\text { with no strong } \\
\text { relationship be- } \\
\text { tween them }\end{array}$ \\
\hline $\begin{array}{c}\text { Mathematics is a conven- } \\
\text { ient way of representing } \\
\text { physical phenomena }\end{array}$ & 18 & 0 \\
\hline $\begin{array}{c}\text { Physics and math are inde- } \\
\text { pendent with no strong } \\
\text { relationship between them }\end{array}$ & 1 & 1 \\
\hline
\end{tabular}

That result is validated by the results of $\mathrm{X}^{2}-$ Testing for Independence: $\mathrm{X}^{2}=9.477, p=0.002(<0.05)$, so the two variables can be regarded as dependent and McNemar test for equality of percentages $(p=1.000)$.

\section{CONCLUSIONS}

This paper presents a combined approach that is the computational experiment via electronic worksheets in Mathematica. The approach is based on the principles of Discovery learning expanded with the principles of constructivist, socio-cultural and adult learning theories, the concept of cognitive tools and the views on which the computational experiment is founded.

Mathematica is a very promising cognitive tool for Mathematics and Science Higher Education, since its notation, its function-based structure and the possibilities it offers in plotting graphs and making complex calculations make it an ideal tool-intellectual partner.

We propose the creation and use of electronic worksheets in Mathematica, containing the phases of the computational experiment, in the environment of a cognitive tool, electronic worksheets that include:

A) The hypotheses space, where the students in cooperation with the teacher state the hypotheses of the problem/problems to be studied.

B) The experiments space, that includes simulation based discovery learning activities.

C) The predictions space, where the results formulated through experimentation in the experiments space are checked with the analytical solutions of the problem/ problems, in order to check their credibility.

This paper also presents a case study concerning the application of the computational experiment via electronic worksheets in ASPETE, during the spring semester of the 
academic year 2008-09. 20 students participated voluntarily in the study, attending the course "Pedagogical Applications of Computers", $40 \%$ of who were males and $60 \%$ females.

The students' scores before and after the application of the approach present significant differences, making a shift from mean score 3.35 before the approach to 6.15 afterwards.

The difference between the students' scores before and after the application of the approach was also validated by the results of the Inferential Analysis and specifically via the Paired Samples t-test, as the Pearson's correlation coefficient showed a strong linear correlation between the two variables and both the $95 \%$ confidence interval and the value of $t$-test showed that there is difference in the mean scores of the students, with the mean value in students' scores before the approach to be lower than the mean value in students' scores after the approach.

Students after the approach showed higher percentages both in passing grades ( 5 and above) and higher ( 8 and above) and excellent grades (9 or 10).

Students' beliefs on Physics and Mathematics do not present significant change compared before and after the application of the computational experiment via electronic worksheets regarding Independence, Concepts, Reality link and Math link as studied by the corresponding Crosstabulation Tables. These results were also validated by the results of the Inferential Analysis, both by $\mathrm{X}^{2}-$ Testing for Independence and by McNemar test for equality of percentages.

Students' beliefs regarding Coherence seem to present significant change before and after the application of the approach, by the corresponding Crosstabulation Table, a result validated by $\mathrm{X}^{2}-$ Testing for Independence. However McNemar test for equality of percentages did not show a statistically significant difference in the students' beliefs.

In answering the two research questions posed at the Methodology of the study section of the paper, we can conclude that there was a significant change in students' scores that can be attributed to the application of the computational experiment via electronic worksheets. However there was not a significant shift on students' beliefs regarding Physics and Mathematics, a result that can be attributed to the fact that students in Mathematics and Science Higher Education have established beliefs for Physics and Mathematics, generally favourable ones, since they have chosen that direction in their studies after their Entry Examinations, but also since they have come in contact with a series of courses that have reinforced those beliefs.

The application of the computational experiment via electronic worksheets in Mathematica can therefore be characterized as successful, providing to Higher Education's teachers a powerful tool in order to introduce and successfully implement discovery learning activities in their courses combined with the powerful method of the computational experiment. The students in that context can develop both Mathematics and Science knowledge and skills more effectively, come in contact with the possibilities cognitive tools have to offer, but also come in contact with the Computational Science, a domain that has much to offer in Mathematics and Science Education.

\section{REFERENCES}

[1] Bruner, J. (1960). "On Learning Mathematics". The Mathematics Teacher, 53, 610-619.

[2] Bruner, J. (1966). Towards a Theory of Instruction. Cambridge: Belknap Press.

[3] Carlsen, O. and Andre, T. (1992). Use of a microcomputer simulation and conceptual change text to overcome student preconceptions about electric circuits. Journal of Computer-Based Instruction. v19. 105-109.

[4] Chang, K., Chen, L., Lin, Y., Sung, T. (2008). Effects of learning support in simulation-based physics learning. Computers \& Education, Volume 51.

[5] Colaso, V., Kamal, A., Saraiya, P., North, C., McCrickard, S., \& Shaffer, C. (2002). Learning and retention in data structures: A comparison of visualization, text, and combined methods. In Paper presented at the proceedings of ED-MEDIA 2002 world conference on educational multimedia/hypermedia and educational telecommunications.

[6] Crawford, K. (1996). "Vygotskian approaches to human development in the information era". Educational Studies in Mathematics, 31, 43-62. (doi:10.1007/BF00143926)

[7] Cross K. P. (1981). Adults as learners. San Francisco: JosseyBass.

[8] De Jong, T. (2006). Computer Simulations: Technological Advances in Inquiry Learning. Science 2006.

[9] Derry, S. J. (1990). Flexible cognitive tools for problem solving instruction. Paper presented at the annual meeting of the American Educational Research Association, Boston, April.

[10] diSessa, A. (1991). "Local sciences: Viewing the design of human-computer systems as cognitive science". In Carroll, J. M. Designing Interaction: Psychology at the Human-Computer Interface. Cambridge University Press p. 162-202.

[11] Drucker P.F. (1989). The New Realities. Oxford: Heinemann Professional Publishing.

[12] Fund, Z. (2007). The Effects of Scaffolded Computerized Science Problem-Solving on Achievement Outcomes: A Comparative Study of Support Programs. Journal of Computer Assisted Learning, v23 n5.

[13] Gilbert, J. K. and Boulter, C.J. (1994). Modelling across the curriculum: the demands and actualities of a unifying theme from science in the primary school. Paper presented at the 7th Symposium Science and Technology Education in a Demanding Society (De Koningshof Veldhoven, The Netherlands).

[14] Gray, A. (1998). Modern Differential Geometry of Curves and Surfaces with Mathematica. CRC Press.

[15] Guzdial, M. (1995). "Software-realized scaffolding to facilitate programming for science learning". Interactive Learning Environments, 4(1), 1-44. (doi:10.1080/1049482940040101)

[16] Hammer, M. and Champy, J. (1993). Reengineering the Corporation: A manifesto for business Revolution. Harper Business, New York.

[17] Hestenes, D. (1999). New Foundations for Classical Mechanics. Kluwer Academic Publishers, Dordrecht, 2nd edition, 1999.

[18] Jonassen, D. H. (2000). Computers as Mindtools for Schools: Engaging Critical Thinking (2nd Edition). New Jersey: Prentice Hall, Inc.

[19] Kemmis, S., Atkin, R. \& Wright, E. (1977). How do Students Learn? Working papers on CAL. Norwich: Centre for Applied Research in Education, University of East Anglia.

[20] Klahr, D. and Dunbar, K. (1988). Dual space search during scientific reasoning. Cognitive Science, 12, 1-48.

[21] Knowles, M. (1984a). Andragogy in Action. San Francisco: Jossey-Bass.

[22] Knowles, M. (1984b). The Adult Learner: A Neglected Species ( $3 r d E d$.). Houston, TX: Gulf Publishing.

[23] Kommers, P. A. M., Jonassen, D. H. and Mayes, T. M. (1992). Cognitive tools for learning. Heidelberg, Germany: SpringerVerlag.

[24] Landau, R. H. Paez, J. \& Bordeianu, C. (2008). A Survey of Computational Physics Introductory Computational Science. Princeton University Press, Princeton and Oxford. 


\section{DisCOVERY LEARNING AND THE COMPUTATIONAL EXPERIMENT IN HIGHER MATHEMATICS AND SCIENCE EDUCATION: A COMBINED APPROACH}

[25] Luo, W., Stravers, J., and K. Duffin, 2005, "Lessons Learned from Using a Web-based Interactive Landform Simulation Model (WILSIM) in a General Education Physical Geography Course," Journal of Geoscience Education, v. 53, n. 5, p. 489-493.

[26] Pea, R. D. (1985). "Beyond amplification: using the computer to reorganize mental functioning". Educational Psychologist, 20 (4). (doi:10.1207/s15326985ep2004_2)

[27] Perkins, D. N. (1993). "Person-plus: A distributed view of thinking and learning". In G. Salomon (Ed.), Distributed Cognitions: Psychological and Educational Considerations. Cambridge: Cambridge University Press.

[28] Psycharis, S. (2008). Computerized Models in Physics Teaching: Computational Physics and ICT. International Journal of Learning, 2008, Volume 15, Number 9, 111-116.

[29] Reamon, D. and Sheppard, S.D. (1997), "The Role of Simulation Software in an Ideal Learning Environment," ASME Design Engineering Technical Conferences, Sacramento, CA.

[30] Redish, E. \& Hammer, D. (2000). Proposal to the NSF ROLE Competition June 1, 2000 Learning How to Learn Science: Physics for bioscience majors.

[31] Regan, M. and Sheppard, S. (1996). Interactive multimedia courseware and the hands-on learning experience: An assessment. Journal of Engineering Education. v85. 123-131.

[32] Scardamalia, M., \& Bereiter, C. (1996). Computer support for knowledge-building communities. In T. Koschmann (Ed.), CSCL: Theory and practice of an emerging paradigm (pp. 249-268). Hillsdale, NJ: Lawrence Erlbaum Associates.

[33] Shiflet, A. B. and Shiflet, G., W. (2006). Introduction to Computational Science: Modeling and Simulation for the Sciences. Princeton University Press.

[34] Shunn, C. and Klahr, D. (1995). A 4-space model for scientific discovery. Paper presented at the AAAI Symposium Systematic Methods of Scientific Discovery, Menlo Park, CA.

[35] Sinclair, H. (1987). "Constructivism and the psychology of mathematics". Proceedings of the Eleventh Annual Psychology of Mathematics Education Conference.

[36] Sloot, P. (1994). Lecture on Parallel Scientific Computing and Simulations. CERN school on computing, Sopron, Hongary August 1994.
[37] Soloway, E. (1993). Should we teach students to program? Communications of the ACM, 36 (10), 21-24. (doi:10.1145/ 163430.164061)

[38] Steffe, L., Cobb, P. \& Von Glasersfeld, E. (1988). Construction of arithmetical meaning and strategies. New York: Springer-Verlag.

[39] Thompson, B. (1985). "Experience, problem solving and learning mathematics: Considerations in developing mathematics curricula". In Silver E.A. (ed.): Teaching and Learning mathematical problem solving: Multiple research Perspectives. Hillsdale N. J.: Lawrence Erlbaum Associates.

[40] Torrence, Br. and Torrence, E. (1999). The Students Introduction to Mathematica. Cambridge University Press.

[41] Van Joolingen, W. R. and De Jong, T. (1997). An extended dual search space model of learning with computer simulations. Instructional Science, 25, 307-346.

[42] Vygotsky, L. S. (1978). Mind in Society. Cambridge, MA: Harvard University Press.

[43] Wolfram, St. (1996). The Mathematica Book, 3rd Edition. Cambridge University Press.

[44] Zemke R. \& Zemke S. (1984). "30 Things We Know for Sure About Adult Learning". Innovation Abstracts, 6 (8).

\section{AUTHORS}

Professor A. Kyriazis is with the Department of Statistics and Insurance Sciences of the University of Piraeus, Greece (e-mail: kyriazis@ypepth.gr).

Associate Professor S. Psycharis is with the General Department of Education of ASPETE (School of Pedagogical and Technological Education), in Athens, Greece (e-mail: spsycharis@gmail.com).

Dr K. Korres (Corresponding author) is with the General Department of Education of ASPETE (School of Pedagogical and Technological Education), in Athens, Greece as a Scientific Associate (e-mail: kostas_korres@yahoo.gr).

Submitted 17 August 2009. Published as resubmitted by the authors on 18 November 2009. 